\title{
Spatiotemporal Analysis of Active Fires in the Arctic Region during 2001-2019 and a Fire Risk Assessment Model
}

\author{
Zhen Zhang ${ }^{1,2}{ }^{\oplus}$, Leilei Wang ${ }^{1}$, Naiting Xue ${ }^{1}$ and Zhiheng Du ${ }^{2, *}$ \\ 1 School of Spatial Informatics and Geomatics Engineering, Anhui University of Science and Technology, \\ Huainan 232001, China; zhangzhen@aust.edu.cn (Z.Z.); 2020201381@aust.edu.cn (L.W.); \\ 2018200893@aust.edu.cn (N.X.) \\ 2 Key Laboratory of Cryospheric Science, Northwest Institute of Eco-Environment and Resources, Chinese \\ Academy Sciences, Lanzhou 730000, China \\ * Correspondence: zhihengdu@lzb.ac.cn
}

Citation: Zhang, Z.; Wang, L.; Xue, N.; Du, Z. Spatiotemporal Analysis of Active Fires in the Arctic Region during 2001-2019 and a Fire Risk Assessment Model. Fire 2021, 4 , 57. https://doi.org/10.3390/ fire 4030057

Academic Editors: Daniela Stroppiana and Mirco Boschetti

Received: 19 July 2021

Accepted: 31 August 2021

Published: 2 September 2021

Publisher's Note: MDPI stays neutral with regard to jurisdictional claims in published maps and institutional affiliations.

Copyright: (c) 2021 by the authors. Licensee MDPI, Basel, Switzerland. This article is an open access article distributed under the terms and conditions of the Creative Commons Attribution (CC BY) license (https:// creativecommons.org/licenses/by/ $4.0 /)$.

\begin{abstract}
The increasing frequency of active fires worldwide has caused significant impacts on terrestrial, aquatic, and atmospheric systems. Polar regions have received little attention due to their sparse populations, but active fires in the Arctic cause carbon losses from peatlands, which affects the global climate system. Therefore, it is necessary to focus on the spatiotemporal variations in active fires in the Arctic and to assess the fire risk. We used MODIS C6 data from 2001 to 2019 and VIIRS V1 data from 2012 to 2019 to analyse the spatiotemporal characteristics of active fires and establish a fire risk assessment model based on logistic regression. The trends in active fire frequency based on MODIS C6 and VIIRS V1 data are consistent. Throughout the Arctic, the fire frequency appears to be fluctuating and overall increasing. Fire occurrence has obvious seasonality, being concentrated in summer (June-August) and highest in July, when lightning is most frequent. The frequency of active fires is related to multiple factors, such as vegetation type, NDVI, elevation, slope, air temperature, precipitation, wind speed, and distances from roads and settlements. A risk assessment model was constructed based on logistic regression and found to be accurate. The results are helpful in understanding the risk of fires in the Arctic under climate change and provide a scientific basis for fire prediction and control and for reducing fire-related carbon emissions.
\end{abstract}

Keywords: active fires; fire risk assessment; arctic; MODIS; VIIRS

\section{Introduction}

Fire plays an important role in the exchange and circulation of carbon and energy in the earth's biosphere and atmospheric system and causes serious air pollution (PM2.5 [1], carbon oxide, $\mathrm{CO}_{2}$, and carbon monoxide, $\mathrm{CO}$, emissions [2]), soil degradation [3], ecological damage [4], economic losses [5], and damage to human health [6]. With global warming, more frequent extreme heatwaves and droughts have increased the frequency of wildfires, which have had serious impacts on terrestrial ecosystems $[7,8]$. The aboveground biomass and soil of terrestrial ecosystems, especially forests, are important as carbon pools for mitigating climate warming [8]. A warming climate will lead to an increase in forest fires, which will significantly affect the functioning of terrestrial ecosystem-mediated carbon sinks [8]. In addition to the aboveground biomass, forest fires also have great impacts on soil organic matter layers [9]. Fires that burn deep into the soil cause the loss of soil carbon and release large amounts of carbon into the atmosphere, which further aggravates climate warming and creates a vicious cycle [8].

The terrestrial ecosystem of the Arctic region is an important part of the global ecosystem. With continuous warming of the global climate, the carbon pool in the circumpolar permafrost will be gradually disturbed and may enter the atmosphere in the form of methane gas, which is an important driver of environmental change [10]. Naturally occurring fires in the Arctic include not only wildfires and forest fires, but also peat fires [11]. 
Peatlands are the most carbon-intensive ecosystems on Earth [12]; when they burn, they release ancient carbon into the atmosphere. Unlike forests, peatlands do not recover after burning. Hugelius et al. [10] believe that northern peatlands may eventually turn from net carbon sinks into net carbon sources and further accelerate climate change. Nearly half of the world's peatland reserves are located around the Arctic Circle between latitudes of $60-70^{\circ}$ north [10]. The Arctic is warming rapidly and Arctic wildfires are making massive carbon emissions [13]. In addition, Arctic fires control many important ecosystem processes [14]. Therefore, understanding the spatiotemporal distribution pattern of fire frequency in the Arctic region is helpful in (1) understanding the occurrence of active fires, (2) providing a reference for the impact assessment of Arctic fires, and (3) providing a scientific basis for response analyses of climate change and extreme weather events.

Early detection of fires is crucial to reducing the ultimate damage. Traditionally, longrange wildfire detection mainly relies on ground-based equipment such as watchtowers and aviation patrol, but it is often inefficient and has many omissions. At present, early detection and spatial analysis of fires mainly rely on satellite remote sensing. Satellite remote sensing is a rapid method of monitoring active fires. Its long-term data archives can be used to analyse the spatiotemporal distributions of active fires at large scales and over long periods. Dozier [15] proposed that the sub-pixel method can be used for satellite sensors in thermal infrared band to identify the temperature and area of the fire at sub-pixel resolution. Langaas et al. [16] improved Doizer's model by using the image of Advanced Very High Resolution Radiometer (AVHRR) carried by National Oceanic And Atmospheric Administration (NOAA) satellite, and obtained the frequency value of band 3 based on the histogram to identify potential fire point pixels. Subsequently, many scholars [17-19] improved the fire detection algorithm, and more satellite systems that collect multi-source images have been used to monitor the location and extent of active fires around the world, such as Moderate-resolution Imaging Spectroradiometer (MODIS) and Visible infrared Imaging Radiometer (VIIRS). These remote sensing data play an important role in fire detection and temporal and spatial variability [20-23]. Although the spatial resolutions of ASTER, Landsat, and Sentinel-2 data are relatively high and play an important role in active fire monitoring [24-26], their temporal resolution is relatively low, such that short fire events may be missed. MODIS provides data recorded since 2000 and plays an important role in active fire monitoring [27,28]. Small fires (e.g., $0.01 \mathrm{~km}^{2}$ ) of short duration $(<1-2 \mathrm{~h})$ can be detected [29], but active fires caused by smouldering may be underestimated in small areas. VIIRS can provide active fire data at a higher spatial resolution than MODIS, and has played an important role in active fire monitoring since 2012 [30]. The NASA Fire Information for Resource Management System (FIRMS) provides near-real-time active fire position vector information derived from MODIS and VIIRS data. FIRMS active fire data has been applied to fire situation assessment [31], economic loss assessment [32], air pollution assessment [33], climate change simulation [34], and other aspects. Currently, active research is focused on North and South America (Amazon) [35,36], Central Africa [37], Russia [38], China [22], and Southeast Asia [39]. However, few studies have focused on active fires across the entire Arctic region. Although some studies have focused on active fires in Siberia [40,41] and Alaska [42], the spatial and temporal distribution patterns of active fires in the Arctic remain unclear and research on fire risk assessment remains lacking.

Fire risk can be defined as the probability of a fire occurring and the potential damage that may be caused at a given location [43]. Garcia et al. [44] used logistic regression model to predict the probability of fire caused by human factors. Then, some scholars $[45,46]$ further proved that logistic regression model is a valuable tool for predicting fire. Rollings et al. [47] used remote sensing image band digital numbers and derived spectral indices in their predictive indicators to map fire regime. Subsequently, many scholars [48-50] applied the logistic regression model to fire risk assessment and prediction. Many other fire risk models have been developed in recent years, such as Artificial Neural Networks [51], maximum entropy algorithms [52], classification trees [53], and Random 
Forests [54]. The advantage of logistic regression is that variables can be continuous, classified, or any combination of the two types, and normal distribution is not necessary [50]. Therefore, logistic regression is a better method in fire research at present [50]. This approach requires a certain amount of prior knowledge about what the fire risk is related to [48-50]. In the past, many scholars have made explorations and mainly concluded that factors such as terrain, vegetation, climate, and human beings are highly related to fire risk [48-50]. There is a lack of previous literature on Arctic fire risk assessment, so we used these factors selected for modelling.

Therefore, the aims of this paper were to (1) analyse the spatial and temporal distribution patterns of active fires in the Arctic region from 2001 to 2019, so as to provide a research basis for future fire prevention work; and (2) quantitatively analyse the relationships between fire and its influences and construct a risk assessment model to understand the causes of fire and promote effective prevention measures.

\section{Study Area, Data, and Methods}

\subsection{Study Area}

In this study, the Arctic region refers to the region north of the Arctic Circle $\left(66^{\circ} 34^{\prime} \mathrm{N}\right)$, which is geographically surrounded by Asia, Europe, and North America (Figure 1). Its total area is $2.1 \times 10^{7} \mathrm{~km}^{2}$, accounting for about $1 / 25$ of the total area of the earth, and has a land area of about $8 \times 10^{6} \mathrm{~km}^{2}$. The land within the Arctic Circle is divided into eight circumpolar countries: Russia, the United States, Canada, Denmark, Norway, Iceland, Sweden, and Finland. Surrounding the Arctic Ocean are the permafrost regions of Asia, Europe, and northern North America, which are mostly flat and treeless. The vegetated area of the Arctic is only about $5.05 \times 10^{6} \mathrm{~km}^{2}$ in area, of which about $40 \%$ is tundra and $26 \%$ is upright shrub [55]. Canada has the most diverse terrain in the High Arctic and is mainly associated with abundant barren terrain and low-shrub tundra, while Russia is the largest region in the Low Arctic and predominant contains low-shrub tundra. Arctic vegetation is particularly sensitive to climate change, especially change in summer temperatures. Since the average temperature in July is higher than the freezing point at the most territory of continental Arctic, a temperature change of a few degrees in summer will change the total heat required for plant growth several-fold, leading to significant changes in vegetation structure, plant productivity, plant communities and species diversity [55]. The Arctic has a cold climate with long winters and short summers. The northern margins of Europe, Asia, and North America, as well as parts of the Greenland coast and several islands in the Arctic Ocean, have a polar tundra climate. Greenland and other islands in the Arctic Ocean have a polar ice field climate, are covered by snow and ice year-round, and receive little rainfall [56].

\subsection{Data}

\subsubsection{FIRMS Active Fire Data}

The FIRMS was produced by NASA and the United Nations Food and Agriculture Organization to provide near-real-time active fire data (https: / / firms.modaps.eosdis.nasa. gov/active_fire/\#firms-shapefile, accessed on 9 August 2021). It provides two global active fire datasets: MODIS Collection 6 (C6, $1 \mathrm{~km}$; from 11 November 2000) and VIIRS Version 1 (V1, $375 \mathrm{~m}$; from 20 January 2012). A consistency detection algorithm was used to compare the MODIS C6 and VIIRS V1 active fire data [57]. The two datasets were found to have good consistency and be suitable for use in a combined way to support fire management and other related scientific applications [33,58,59]. MODIS data from 2001 onwards was used, as 2001 was the first complete year of data. FIRMS active fire data was processed with ArcGIS software (Version 10.0, Environmental Systems Research Institute, Inc., RedLands, United States). 


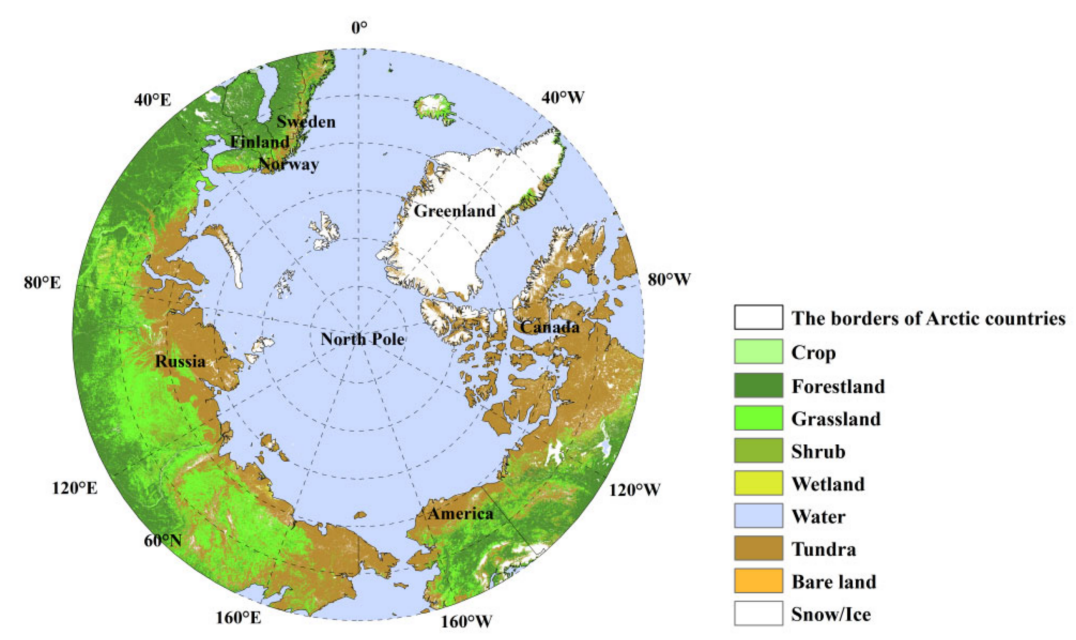

Figure 1. Land cover in the Arctic region (Land cover data was download from https://ladsweb. modaps.eosdis.nasa.gov/search/order/1/MCD12Q1--6, accessed on 9 August 2021; the projection used in this map is Sphere Lambert Azimuthal equal area project).

\subsubsection{MCD12C1 Land Cover Data}

The MCD12C1 (MODIS Land Cover Climate Modeling Grid Product) [60] provides annual global maps of land cover types at a spatial resolution of $500 \mathrm{~m}$. MCD12C1 data was download from https://ladsweb.modaps.eosdis.nasa.gov/search/order/1/MCD12Q1--6 (accessed on 9 August 2021). The International Geosphere-Biosphere Programme (IGBP) classification was used in our study, which includes 17 land cover types. MCD12C1 Land Cover data was processed with ArcGIS and ENVI software (Version 5.0, Exelis Visual Information Solutions, Inc., Colorado, United States).

\subsubsection{MODIS NDVI Data}

NDVI data were extracted from MOD13A1 and MOD13C2, which were downloaded from the NASA website, and had a temporal resolution of 16 days and a spatial resolution of $500 \mathrm{~m}$. MODIS NDVI Data was processed with ArcGIS and ENVI software (Version 5.0, Exelis Visual Information Solutions, Inc., Colorado, United States).

\subsubsection{Lightning Climatology Gridded Product}

The lightning climatology gridded product (https:/ / ghrc.nsstc.nasa.gov/lightning/ data / data_lis_otd-climatology.html, accessed on 9 August 2021) was derived from the Optical Transient Detector (OTD) instrument from May 1995 to December 2000 and from its successor, the Lightning Imaging Sensor (LIS) instrument, for December 1997 to 2015. The dataset includes lightning rate densities at $2.5^{\circ} \times 2.5^{\circ}$ and $0.5^{\circ} \times 0.5^{\circ}$ spatial resolutions. We used Panoply software to plot monthly lightning rate maps from April to September in the Arctic using LIS/OSD $0.5^{\circ}$ high-resolution monthly climate (HRMC) data [61]. These data are global flash rate density averaged over the 16 years (1995-2010) of the TRMM LIS and OTD missions.

\subsubsection{ERA 5 Climate Reanalysis Data}

ERA 5 climate reanalysis data (https:/ /cds.climate.copernicus.eu/cdsapp\#!/dataset/ reanalysis-era5-single-levels-monthly-means?tab=overview, accessed on 9 August 2021) of global climate and weather is fifth-generation ECMWF reanalysis data and provides global monthly average grid data from 1979 to present. It includes nearly 2-m air temperature, precipitation and 10-m wind speed data, global coverage, one-month temporal resolution and spatial resolution of $0.25^{\circ}$. ERA 5 climate reanalysis data was processed with ArcGIS software (Version 10.0, Environmental Systems Research Institute, Inc., RedLands, United States). 


\subsubsection{Populated Places and Roads Data}

Data on populated places and roads at 1:10 million scale were downloaded from the Natural Earth website (www.naturalearthdata.com, accessed on 9 August 2021). Populated places data is a location containing capitals, major cities, towns, and smaller towns in sparsely inhabited regions. The data included population, which were derived from the LANDSCAN dataset (https://landscan.ornl.gov/, accessed on 9 August 2021) maintained and distributed by the Oak Ridge National Laboratory. Roads data were derived from CEC North America Environmental Atlas and the other region atlas. We used ArcGIS software to build a $0.05^{\circ} \times 0.05^{\circ}$ fishnet. The nearest neighbour analysis tool was used to measure the distance from the centre of each fishnet grid to the nearest populated place and road to generate a layer of distance data.

\subsection{Methods}

\subsubsection{Theil-Sen Slope Method}

The Theil-Sen slope (TS) method is generally used to detect pixel-level linear trends in fire products. The TS square method is a mature nonparametric method proposed by Theil in 1950 [62] and modified by Sen in 1968 [63]. Compared with traditional linear regression, the TS method is insensitive to outliers. This makes it more suitable for linear trend estimation, particularly for time series with large interannual variations. The formula of the TS method is:

$$
\Delta=\operatorname{median}\left(\frac{x_{j}-x_{i}}{j-i}\right)
$$

where median is a median function, $x_{i}$ is the value at point $i$, and $x_{j}$ is the value at point $j$. When $\Delta>0$, it is considered that the time series has an increasing trend; when $\Delta<0$, the trend is falling.

\subsubsection{Mann-Kendall Test}

The Mann-Kendall (MK) test [64] was used to determine the significance of long-term trends. This method is also nonparametric and does not require the sample to satisfy any particular distribution. An important method of trend analysis is to combine the MK and TS methods. TS can reduce noise interference well but cannot judge the significance of a trend in a series; while MK can, it does not require the series to have a particular distribution, and is insensitive to outliers. The statistic $S$ is calculated as follows [64]:

$$
\begin{aligned}
& S=\sum_{i=1}^{n-1} \sum_{j=i+1}^{n} \operatorname{sgn}\left(x_{j}-x_{i}\right) \\
& \operatorname{sgn}\left(x_{j}-x_{i}\right)=\left\{\begin{array}{l}
1, x_{j}-x_{i}>0 \\
0, x_{j}-x_{i}=0 \\
-1, x_{j}-x_{i}<0
\end{array}\right.
\end{aligned}
$$

Depending on the value of $n$, the statistics are calculated in different ways. If $n<$ 10, Equation (2) was used to calculate $S$ and then a bilateral trend test was used. Using the level of significance $\alpha$, if $|S|>S_{\alpha / 2}$, then the trend of the sequence is considered significant. If $S>0$, the trend is positive; if $S=0$, the sequence has no trend; and if $S<0$, the trend negative.

If $n \geq 10, S$ approximately obeys a standard normal distribution and the Z-statistic should be used for bilateral trend testing, the formula for which is $[64,65]$ :

$$
\begin{aligned}
& Z=\left\{\begin{array}{l}
\frac{S-1}{\sqrt{\operatorname{Var}(S)}}, S>0 \\
0, S=0 \\
\frac{S+1}{\sqrt{\operatorname{Var}(S)}}, S<0
\end{array}\right. \\
& \operatorname{Var}(S)=\frac{n(n-1)(2 n+5)-\sum_{i=1}^{m} t_{i}\left(t_{i}-1\right)\left(2 t_{i}+5\right)}{18}
\end{aligned}
$$


where $n$ is the total number of data points in the sequence $x_{\mathrm{i}}=\left(x_{1}, x_{2}, \ldots, x_{n}\right), m$ is the number of groups of tied ranks, and $t_{i}$ is the number of data in the tied group. After obtaining $\alpha$, the critical value $Z_{1-\alpha / 2}$ can be obtained from a normal distribution table. If $|Z|>Z_{1-\alpha / 2}$, there is a significant trend in the sequence; otherwise, there is not.

\subsubsection{Average Nearest Neighbour Analysis}

The average nearest neighbour analysis [66] measures the distance between the centre of mass of each element and that of its nearest neighbour, and then calculates the average of all these distances. If the mean distance is less than that of a hypothetical random distribution, the distribution of analysed elements is regarded as clustered. Conversely, if the average distance is greater, the factor is considered to be dispersed. The ratio of the observed mean distance to the expected mean distance is called the average nearest neighbour ratio $(A N N)$ and its formula is [66]:

$$
\begin{gathered}
A N N=\frac{\bar{D}_{\mathrm{O}}}{\bar{D}_{\mathrm{E}}} \\
\bar{D}_{\mathrm{O}}=\frac{\sum_{i=1}^{n} d_{i}}{n} \\
\bar{D}_{\mathrm{E}}=\frac{0.5}{\sqrt{n / A}}
\end{gathered}
$$

where $\bar{D}_{\mathrm{O}}$ and $\bar{D}_{\mathrm{E}}$ are the observed and expected average distances, respectively, $d_{i}$ is the distance between $i$ and the centre of mass of its nearest neighbour, $n$ is the total number of elements, and $A$ is the area of minimum bounding rectangle that includes all elements. We can generate the minimum bounding rectangle in ArcGIS (Minimum Bounding Geometry tool) and calculate its area.

The calculation of $z$-score is as follows [66]:

$$
\begin{gathered}
z=\frac{\bar{D}_{\mathrm{O}}-\bar{D}_{\mathrm{E}}}{S E} \\
S E=\frac{0.26136}{\sqrt{n^{2} / A}}
\end{gathered}
$$

The value 0.26136 is a constant derived from the radius of a circle, the notion for the standard error being based on using a circle divided into equal sectors and finding the number of points, given a hypothetical random distribution, in any given sector [66].

By means of the mean nearest neighbour analysis, we analysed the spatial distribution patterns of active fires based on FIRMS MODIS C6 and VIIRS V1 data.

In the mean nearest neighbour analysis method, the mean nearest neighbour ratio is used to represent the spatial distribution of fires, the z-value is used to represent the degree of fire aggregation and dispersion, and the $p$-value is used to reflect the significance of the results. If $A N N<1$, the pattern of spatial geographical elements is clustered. If $A N N>1$, the pattern is discrete.

\subsubsection{Multicollinearity Testing}

If the degree of multicollinearity between independent variables is severe, the standard error of the regression coefficient estimated by a regression model will be high, resulting in deviation in parameter estimation and, finally, failure of the model's inference [67]. Generally, tolerance or variance inflation factor (VIF) is used for a multicollinearity test [67-69].

The tolerance $(T O L)$ factor was calculated as [68]:

$$
T O L=1-R_{i}^{2}
$$

where $R_{i}$ is the determination coefficient of the linear regression model. If $T O L<0.1$, the multicollinearity among independent variables is significant.

The VIF, which is the reciprocal of TOL, is the ratio coefficient of the variance of the estimated regression coefficient in cases of collinear and non-collinear relationships among 
independent variables [69]. The strength of multicollinearity among independent variables is proportional to VIF. When $0<\mathrm{VIF}<10$, it indicates that there is no multicollinearity among independent variables; when $10<\mathrm{VIF}<100$, it indicates that there is a strong multicollinearity among independent variables; when VIF $>100$, it indicates that there is serious multicollinearity among independent variables [69].

\subsection{Logistic Regression Modelling}

Logical regression is one of the most popular mathematical modelling methods, which can be used to determine the relationship between several independent variables and a dichotomous dependent variable [44]. Logistic regression models are especially suitable for data whose dependent variables follow a multinomial classification. Binary logistic regression is used when the dependent variables are binomial classification variables and the value of the target probability is between 0 and 1 . When the occurrence of fire is taken as the dependent variable, it is a mutually exclusive binomial classification variable. The existence of multiple independent variables at the same time will affect the occurrence of fire, and the influence of independent variables on the dependent variable is not necessarily linear. Therefore, binary logistic regression can be used for fire-risk prediction. In fact, logistic regression analysis has been successfully applied to local- and continental-scale fire prediction [48-50]. Logistic regression is based on the following function:

$$
\begin{gathered}
p=\frac{e^{z}}{1+e^{z}} \\
z=\ln \left(\frac{p}{1-p}\right)=\beta_{0}+\beta_{1} x_{1}+\cdots+\beta_{n} x_{n}
\end{gathered}
$$

where, $\beta_{0}, \beta_{1}, \ldots \beta_{n}$ is the coefficient, $x_{1}, x_{2}, \ldots x_{n}$ is the fire inducement variable, and $p$ is the probability of fire occurrence.

\subsubsection{Selection of Model Samples}

According to the 2001-2019 FIRMS MODIS C6 active fire location data, a total of 75,435 fire sites were randomly selected. Meanwhile, the same amount of non-fire sites (random point without fire occurrence) was also randomly selected. To avoid the distribution of the sample data affecting the choice of variables used in the model, a random selection of $70 \%$ of the sample was used for training (a total of 105,609 fire and non-fire sites) to build the model. The other $30 \%$ of the sample was used for testing the model. We randomly divided training samples and test samples, and repeated it five times. In the five sample tests, fire risk factors satisfying the significance of all the samples in three or more groups were selected for the final training analysis of the whole sample. External testing of model accuracy was carried out using 2018-2019 fire and non-fire site data to determine whether the model could provide good evaluation performance over different time periods.

\subsubsection{Pre-Treatment of Risk Factors}

(1) Multicollinearity testing-Nine factors were selected for multicollinearity testing: vegetation type, NDVI, elevation, slope, 2-m air temperature, precipitation, 10-m wind speed, distance from a road, and distance from a settlement. The results are shown in Supplementary Material Table S1. The tolerance $>0.1$ or VIF $<5$ indicate that there is no common linear relationship between the nine factors, which can be used to build a regression model.

(2) Correlation analysis-In order to verify multicollinearity, we also examine the correlation between various variables. Pearson correlation analysis was conducted for the 9 factors (Supplementary Material Table S2). NDVI was highly correlated with vegetation type and 2-m air temperature; therefore, NDVI was removed from the modelling. 
(3) Significant differences testing-Significance tests were conducted to determine whether the differences between two or more samples were significant and to remove factors that did not differ between fire and non-fire sites. Typically, when $p<0.05$ or $p<0.01$, it indicates that there is a significant or very significant difference between the groups. As shown in Supplementary Material Table S3, the differences in each factor between fire and non-fire sites were all significant at $<0.01$, so no factors were removed.

\subsubsection{Construction of the Logistic Regression Model}

The backward stepwise algorithm [70] was used to introduce factors to carry out training of the logistic regression model. The basic principle of the backward stepwise algorithm is as follows: firstly, all factors are put into the model for training. According to the significance of each factor in the training model, when $p>0.05$, the factor with the largest value of sig is eliminated. Then, the remaining factors were trained in the model again and the screening process was repeated until all the sig values of the remaining factors in the model matched the condition of $p<0.05$.

Logistic regression analysis was carried out on the five training samples to obtain the significance of each factor in the five sample groups. Factors that appeared three times or more in the five sample groups were selected for the full sample group for logistic regression analysis. As shown in Supplementary Material Table S4, in the five sample models, vegetation type, elevation, slope, 2-m air temperature, precipitation, 10-m wind speed, distance from a road and distance from a settlement all showed significance more than three times. Therefore, these 8 factors were selected for logistic regression model training for the whole sample. We used SPSS software (Version 15.0, Statistical Product and Service Solutions, Inc., Chicago, United States) to establish the final logistic regression model according to these 8 variables.

\subsubsection{Precision Evaluation}

The receiver operating characteristic (ROC) [71] is also called the receptive curve because the stimulus received by each point on the curve comes from the same signal and has the same sensitivity. Results are generated under different judgment conditions. A ROC curve plots the false positive rate on the horizontal axis and the hit probability on the vertical axis [71]. Curves are drawn from different results obtained under different judgment conditions and specific stimulus conditions [71].

For the probability model of Arctic fire occurrence established by the binomial logistic regression analysis method, the interpretative ability of driving factors can be tested by the area under the curve (AUC) metric to evaluate the accuracy of the model. The AUC values can range between 0.5 and 1 [71]. If the AUC value is close to 0.5 , it means that the dependent variable of the model is meaningless [71]. At AUC >0.7, the dependent variable of the model has better explanatory ability [71]. AUC values approaching 1 indicate better explanatory ability; that is, the model fits the data better [71].

\section{Results}

\subsection{Annual Fire Changes}

The MODIS C6 and VIIRS V1 active fire location vector data provided by FIRMS for 2000-2019 were used to derive Arctic active fire frequency statistics. The annual average frequency based on MODIS C6 (2001-2019) data was 14,979, and that of VIIRS V1 (2012-2019) was 77,822. The spatial resolution of VIIRS V1 data is higher than that of MODIS C6 data; therefore, it can more easily detect active fires in smaller areas, and more frequent information can be gathered for each fire event. However, MODIS C6 provides a longer time series, which can better reflect the dynamics of active fire frequency. Figure 2 shows that the trends in active fire frequency extracted from MODIS C6 and VIIRS V1 data from 2012 to 2019 are very consistent. The cross-validation of the two kinds of data proves their reliability. 


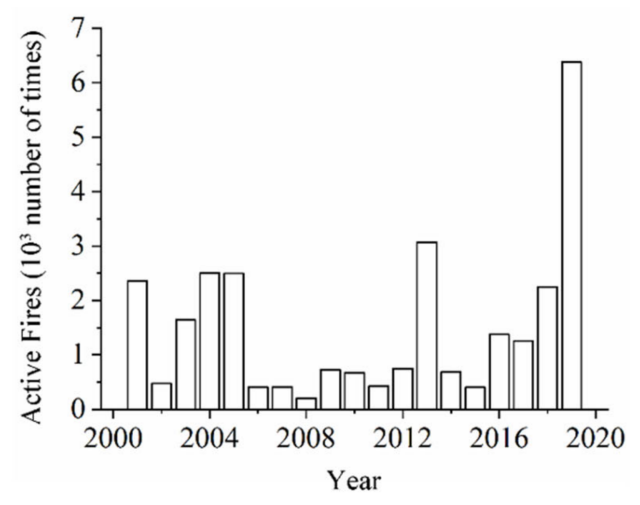

(a)

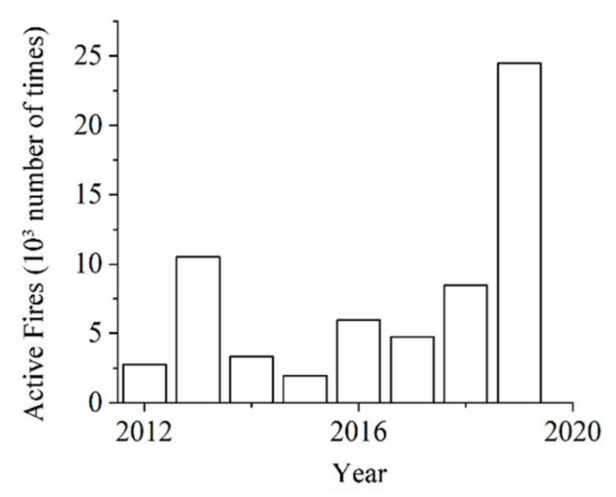

(b)

Figure 2. Annual changes in the numbers of active fires in the Arctic region based on data from MODIS C6 (2000-2019) and VIIRS V1 (2012-2019): (a) MODIS C6 (2000-2019); (b) VIIRS V1 (2012-2019).

According to MODIS C6 results for 2001-2019 (Figure 2a), the active fire number was lowest in 2008 (2009 fires) and highest in 2019 (63,728 fires). VIIRS V1 results for 2012-2019 (Figure 2b) show that the minimum active fire number was in $2015(19,631)$ and the maximum was in 2019 (244,610). Overall, the active fire number appears to have an increasing but fluctuating trend. The number and scale of fires in 2019 were significantly higher than in other years, especially in the summer of 2019, when Arctic temperatures were particularly high [72].

\subsection{Monthly Fire Variation}

The occurrence of active fires had obvious seasonality and was concentrated in June to August (summer). MODIS C6 and VIIRS V1 data show that $92.99 \%$ and $85.57 \%$ of active fires, respectively, occurred in summer (Figure 3). The frequency of active fires was highest in July at $41.42 \%$ and $38.94 \%$, respectively. This may be because of high summer temperatures, low precipitation, lightning, and other factors.

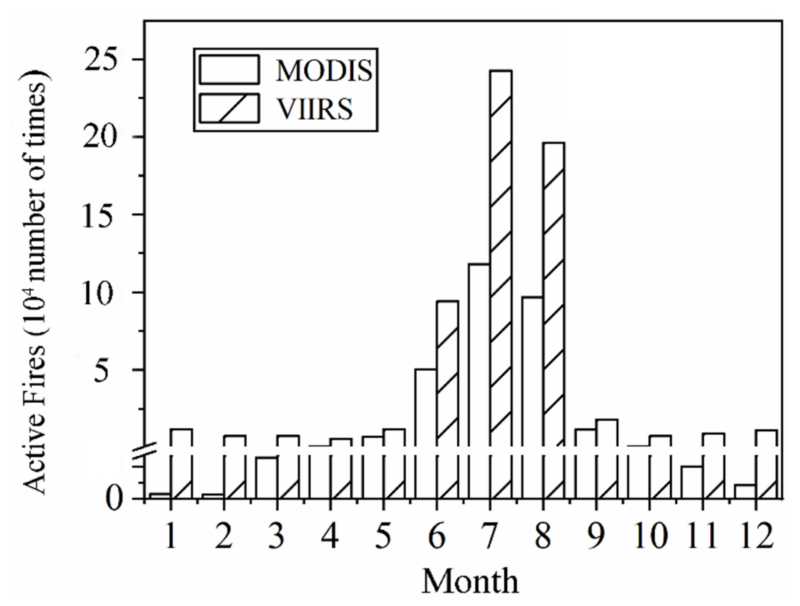

Figure 3. Monthly changes in the numbers of active fires in the Arctic region based on data from MODIS C6 (2000-2019) and VIIRS V1 (2012-2019).

\subsection{Spatial Pattern Analysis}

The occurrence of fires requires a combination of conditions, such as combustibles, ignition sources, etc. However, the types and quantities of combustibles, the climatic conditions, and the intensities of human activities and production vary in different regions of the Arctic, so that the fires in different regions are not evenly distributed. MODIS C6 and VIIRS V1 data showed similar spatial patterns (Figure 4). Most of the active fires were 
in Russia, followed by the United States and Canada's Yukon and Northwest Territories. According to MCD12C1 data, the fire areas of Russia and the United States are mainly covered by sparse shrubs. Canada is mainly grassland but the Yukon and Northwest Territories are mainly tropical savanna and sparse shrub. In these areas, where there is more vegetation and large amounts of dry biomass, fires are possible during the summer months.

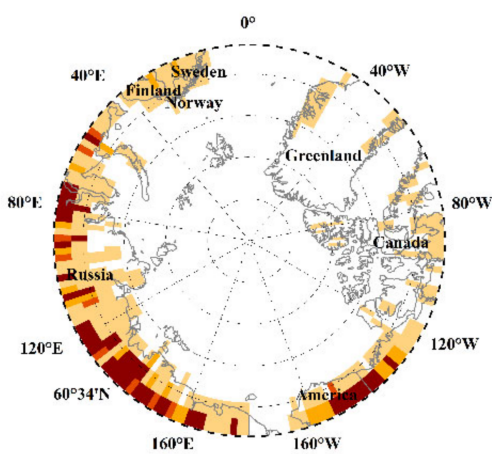

(a)

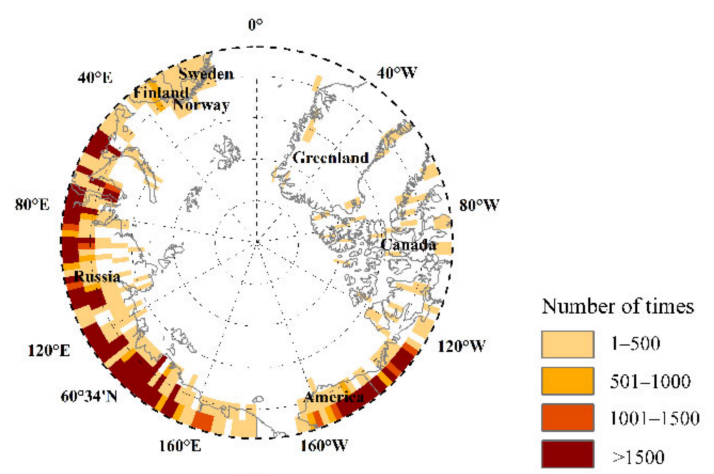

(b)

Figure 4. Spatial patterns in the cumulative numbers of active fires according to (a) MODIS and (b) VIIRS data. The total number of MODIS C6 fires occurring from 2001 to 2019 was counted in the $2^{\circ} \times 2^{\circ}$ grid.

Because the time series of MODIS C6 active fire data is longer, we chose it for analysis. The long-term trend in MODIS C6 fires was analysed by the TS method with significance at $5 \%$ tested by the MK method. The long-term trend in MODIS C 6 fire numbers from 2001 to 2019 (Figure 5) shows that the regions with increasing numbers are concentrated in Russia, and a few regions passed the significance test. There were also increases in the United States, Canada, and Norway, and declines elsewhere, but none of these trends were significant, suggesting that there was no clear long-term trend in fires across much of the Arctic over the past two decades.

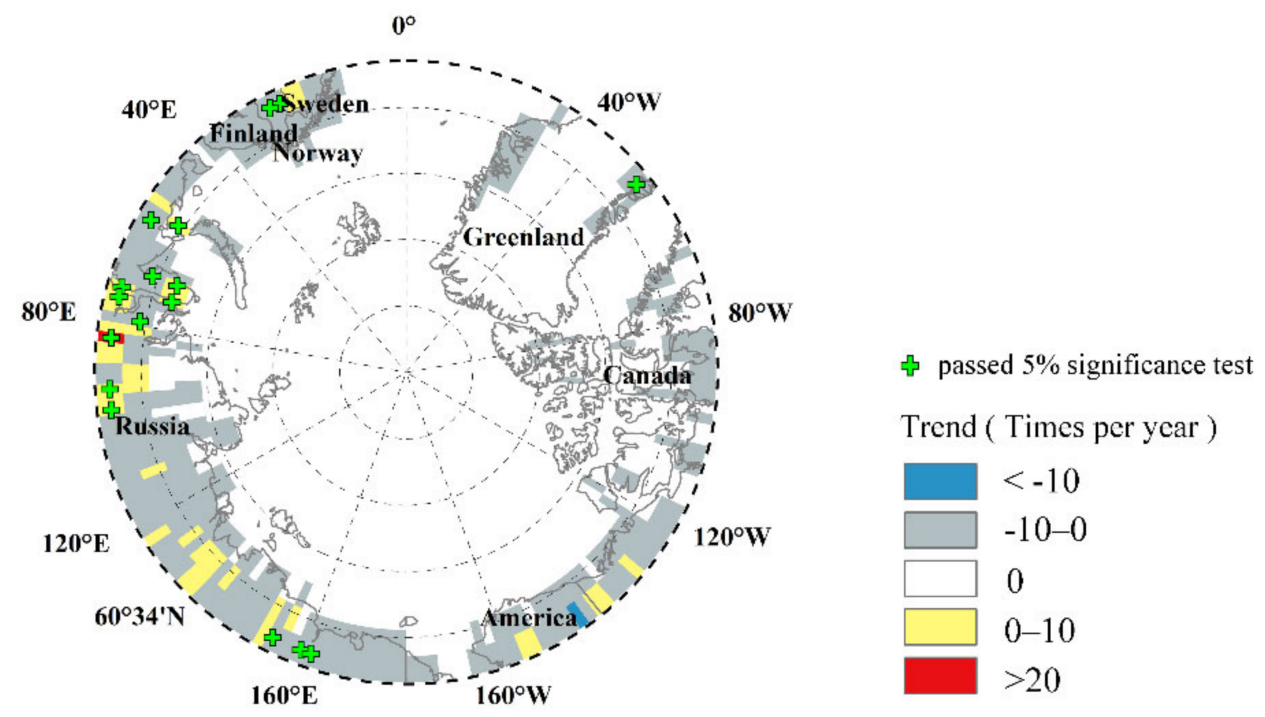

Figure 5. Long-term trend in annual active fire frequency based on MODIS data from 2001 to 2019.

The spatial distribution of fires is related to combustible materials, fire sources, climate, and other factors. These factors differ between regions and have different degrees of influence on the occurrence of fires, so the spatial distribution of fires differs between regions.

The nearest neighbour ratios of MODIS C6 (2000-2019) and VIIRS V1 (2012-2019) active fire data are 0.08 and 0.05 , respectively, which are both $<1$, indicating that both distributions are clustered. The $z$-values of MODIS C6 and VIIRS V1 active fire data are 
-940.19 and -1434.77 , which are far less than the determination value of -0.258 . The $p$-values are both small at far less than 0.01, indicating that the significance of spatial differences is very high. Therefore, the pattern of active fires in the Arctic region is not random but aggregated due to the combined action of certain influencing factors.

\subsection{Factors Influencing the Occurrence of Active Fires in the Arctic Region}

The spatial and temporal distributions of active fires are affected by the types and quantities of combustibles, terrain, climate, ignition sources, and human activities. In this study, the influences of vegetation, terrain, climate, and human activities on active fires were modelled by logistic regression. The influence of each factor is discussed in detail in the following sections.

\subsubsection{Vegetation Factors}

(1) Vegetation Type-Different types of combustibles have different likelihoods of burning. According to the MCD12C1 land cover data, the vegetation types in the Arctic region include evergreen coniferous forest, deciduous coniferous forest, mixed forest, sparse shrubs, woody savanna, savanna, grassland, and sparse vegetation. As shown in Table 1, the trends in active fire frequency in MODIS C6 and VIIRS V1 data are basically consistent. The vegetation types most prone to fire are savanna, sparse shrubs, and woody savanna.

Table 1. Relationship between vegetation type and the percentage of active fires in the Arctic region.

\begin{tabular}{ccccccccc}
\hline Parameter & $\begin{array}{c}\text { Evergreen } \\
\text { Coniferous } \\
\text { Forest }\end{array}$ & $\begin{array}{c}\text { Deciduous } \\
\text { Coniferous } \\
\text { Forest }\end{array}$ & $\begin{array}{c}\text { Mixed } \\
\text { Forest }\end{array}$ & $\begin{array}{c}\text { Sparse } \\
\text { Shrub }\end{array}$ & $\begin{array}{c}\text { Woody } \\
\text { Savanna }\end{array}$ & Savanna & Grassland & $\begin{array}{c}\text { Sparse } \\
\text { Vegetation }\end{array}$ \\
\hline Area * & $0.10 \%$ & $0.06 \%$ & $0.06 \%$ & $44.06 \%$ & $2.43 \%$ & $7.19 \%$ & $32.85 \%$ & $13.25 \%$ \\
Active fires (MODIS) & $3.26 \%$ & $2.32 \%$ & $0.63 \%$ & $15.56 \%$ & $17.70 \%$ & $58.20 \%$ & $1.20 \%$ & $1.13 \%$ \\
Active fires (VIIRS) & $3.16 \%$ & $1.80 \%$ & $0.19 \%$ & $18.65 \%$ & $13.56 \%$ & $58.83 \%$ & $1.65 \%$ & $2.16 \%$ \\
\hline
\end{tabular}

${ }^{*}$ Area is the proportion of each vegetation type area to the land area.

(2) NDVI-The active fire frequency increased first and then decreased with the increases in NDVI (Supplementary Material Figure S1). There were active fires in the regions with NDVI of 0.4 0.8, and the number of fires was the largest when NDVI was 0.65 . When the NDVI value is low, the amount of combustible material is also low and fires do not easily occur. With increases in NDVI, there is more combustible material and chance of fire. There are fewer areas with NDVI greater than 0.65 , so the frequency of active fires is decreasing.

\subsubsection{Terrain Factors}

Terrain not only directly affects the occurrence of fire through local microclimate and airflow, but also indirectly affects the occurrence and spread of fire due to surface runoff and solar radiation, which affect the amount, structure, and moisture of combustibles [73].

(1) Elevation-Elevation affects not only the climate but also the zonal distribution of vegetation, which indirectly affects the occurrence of active fires. Active fires in the Arctic are more frequent below $600 \mathrm{~m}$ and are less frequent with elevation (as shown in Supplementary Material Figure S2, elevation map is shown in Supplementary Material Figure S3). This is because temperatures are lower at higher elevations, precipitation may be more abundant, and there is less vegetation and combustible material.

(2) Slope-Slope can affect the speed and direction of fire spreading. The steeper the slope, the faster the spread, and fire spreads faster uphill than downhill. Precipitation stays for longer on less steep slopes, affecting water loss and fuel moisture. The frequency of active fires in the Arctic region decreases with slope. Fires mainly occur 
on slopes of $<10^{\circ}$, with most occurring on flat land (as shown in Supplementary Material Figure S4, slope map is shown in Supplementary Material Figure S5).

\subsubsection{Meteorological Factors}

Meteorological factors play an important role in the occurrence and propagation of fires. They influence the moisture content of combustible materials and lightning may start fires. In long time scales, changes in meteorological factors affect the climatic zone, and vegetation distributions will move towards the poles and high-altitude areas, thus affecting the accumulation and distribution patterns of fuel. Short-term changes in meteorological factors have direct impacts on fire behaviour and fire-risk weather.

(1) 2-m air temperature-High temperatures can accelerate the evaporation of moisture and drying of fuels such as hay, dead leaves, and conifer needles. The combustion rates are higher under high-temperature conditions than under cold ones, which increases the possibility of fire. Therefore, temperature is a good meteorological factor for fire risk prediction. Fires mainly occurred at temperatures of $10-20^{\circ} \mathrm{C}$. The active fire number first increases and then decreases with increases in 2-m air temperature (Supplementary Material Figure S6).

(2) Precipitation-Precipitation has direct impacts on vegetation water content and ground dryness, and affects the risk and severity of fire. With increases in precipitation, the active fire frequency increases first and then decreases, mainly in the range of $0-3 \mathrm{~mm}$ (Supplementary Material Figure S7). With more precipitation, the chance of fire is almost zero.

(3) 10-m wind speed-Wind can supply oxygen to fires to promote combustion, and affects the direction of fire spread. At higher wind speeds, convection is greater and fire can combustion and spread more rapidly. Under the action of wind, vegetation may dry faster, increasing the possibility of fire. Active fire number in the Arctic region has a non-linear relationship with 10-m wind speed. With increasing wind speed, the active fire number presents a double-peak structure, with the first peak at around $3 \mathrm{~m} / \mathrm{s}$ with great fluctuations and the second peak at around $5 \mathrm{~m} / \mathrm{s}$ with less fluctuation. Active fire frequency was highest at wind speeds of $2-6 \mathrm{~m} / \mathrm{s}$, among which the MODIS number was 144,919 fires, accounting for $89.67 \%$ of the total, and VIIRS active fire frequency was 528,554 fires, accounting for $84.90 \%$ of the total. At $10-\mathrm{m}$ wind speeds $>7 \mathrm{~m} / \mathrm{s}$, there were basically no fires (Supplementary Material Figure S8).

\subsubsection{Human Activity Factors}

With rapid economic development and increasing human activities, forest fires are increasing.

(1) Distance from a road-Roads can be used to reflect the impact of human activities on fire, and human activities become more concentrated with proximity to a road. Behaviours such as smoking by drivers or passengers, as well as some items being transported, can be fire risks. In addition, traffic accidents may cause vehicle fires, and large-scale vehicle fires are more likely to cause the surrounding vegetation to burn. The closer a road, the greater the active fire frequency. Fire frequency decreases sharply with distance from a road (range $=0-3 \mathrm{~km}$ ). Within this range, MODIS C6 and VIIRS V1 data accounted for $56.54 \%$ and $57.18 \%$ of the total active fires. At distances $>20 \mathrm{~km}$, there are basically no fires (Supplementary Material Figure S9).

(2) Distance from a settlement-The greater the population density, the greater the human dependence on surrounding forest resources. In cities, regardless of population density, there are fewer opportunities to have contact with a forest, so the incidence of forest fires is low. The overall trend decreases with distance from settlements and most fires occur within 0-5 km of one (Supplementary Material Figure S10). 


\subsubsection{Lightning}

Arctic active fires are often associated with lightning activity. However, not all cloudto-ground lightning causes fire. Other conditions are also necessary, such as low precipitation. In addition, the probability of fire occurrence due to lightning is related to the vegetation status and meteorological conditions at the lightning location.

The results of lightning activity in the Arctic (Figure 6) show that lightning is relatively frequent in June, July, and August, with the highest activity in July, which is consistent with the monthly distribution of active fires in the Arctic region.
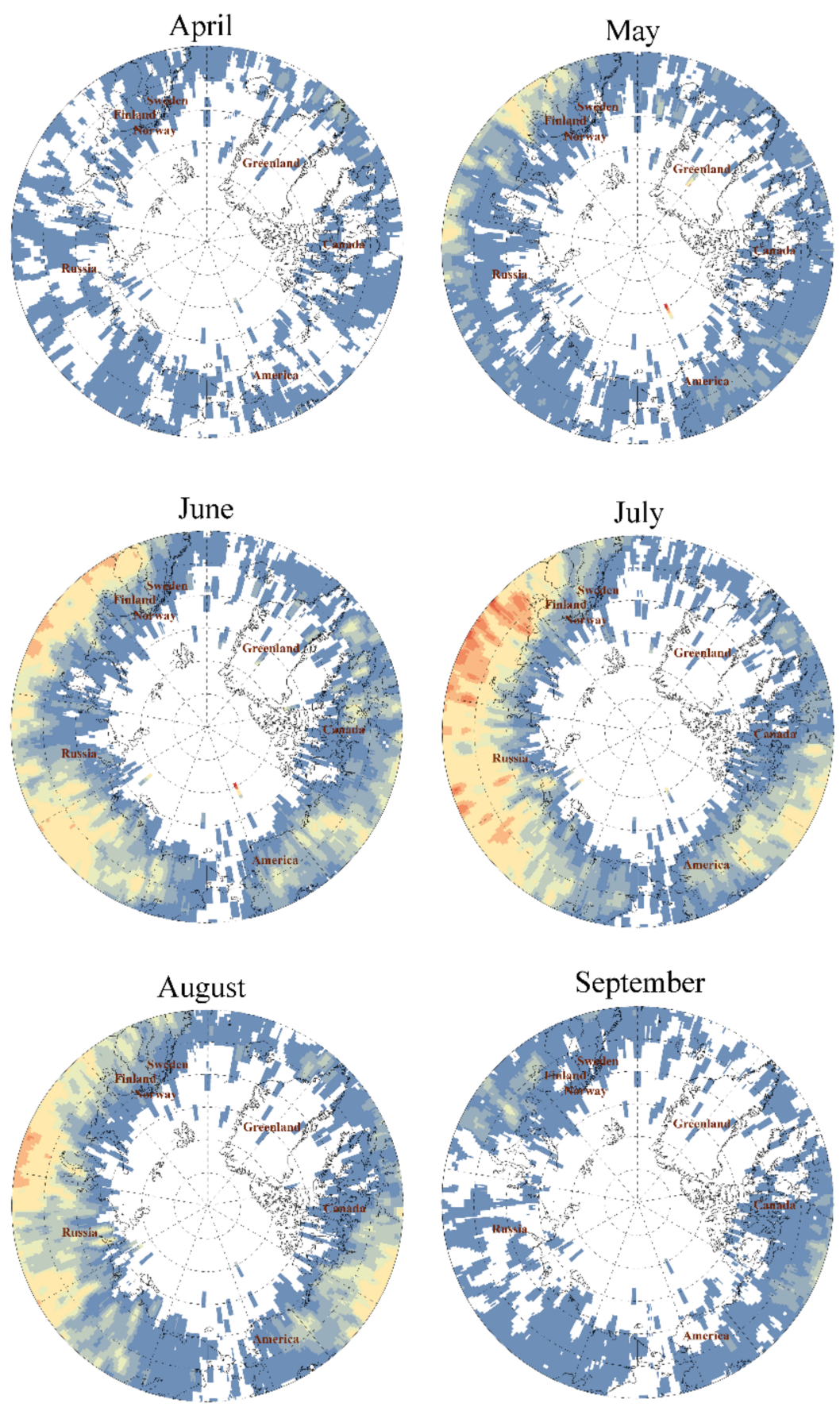

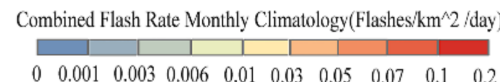

Figure 6. Monthly lightning frequency, April to September, Arctic region. 
Higher temperatures not only increase the number of fires, they also increase the probability of thunderstorms, so the increase in the number of fires is caused by lightning from thunderstorms triggered by higher temperatures. If global warming continues, there will be an increase in fires in high latitudes due to climate change [74].

\subsection{Fire Risk Assessment Results}

The final logistic regression model obtained in our study is:

$$
\begin{aligned}
p= & \frac{e^{z}}{1+e^{z}} \\
z= & -0.04 \times \text { vegetation type }+0.000497 \times \text { elevation } \\
& -0.067 \times \text { slope }+0.193 \times 2 \text { mair temperature } \\
& -0.034 \times \text { pecipitation }-0.358 \times 10 \text { mwind speed } \\
& -0.055 \times \text { distance from the road } \\
& -0.045 \times \text { distance from the settlement } \\
& +0.801
\end{aligned}
$$

where $p$ is the probability of fire occurrence and e is a natural constant.

The AUC of the sample data is 0.85 (Supplementary Material Figure S11a), indicating that the model has high goodness of fit. The AUC of the verification data is 0.93 (Supplementary Material Figure S11b), indicating that the external accuracy verification effect is also good and that this model can be used for active fire prediction in the Arctic region.

A monthly active fire risk index in the Arctic region was calculated according to the above formula. We averaged the risk of all the active fires in a month, and the results (Figure 7) show that the most active fires occur between June and August, which is consistent with the monthly MODIS and VIIRS data and demonstrates the validity of the logistic regression model.

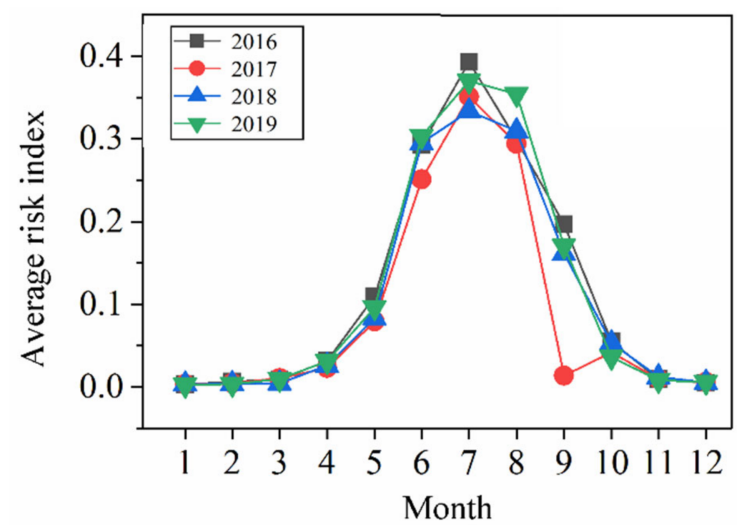

Figure 7. Average fire risk index in the Arctic region.

We calculated the risk indices of active fire sites from 2016 to 2019 by the logistic regression model. An active fire risk index value of $0-0.2$ indicates low risk, $0.2-0.4$ indicates moderately low risk, 0.4-0.6 indicates medium risk, 0.6-0.8 indicates moderately high risk, and $0.8-1$ indicates high risk. Our results (Table 2 ) show that $85.73 \%$ to $94.94 \%$ of the fire sites from 2016 to 2019 are identified by the model as moderately high or high risk. Among them, 2018-2019 is the verification group, and $92.93 \%$ and $94.94 \%$ of the fire sites in the verification group are moderately high or high risk, which demonstrates the accuracy of our evaluation model. 
Table 2. The percentage of points at each active fire risk level to all fires that year.

\begin{tabular}{ccccc}
\hline Risk Level & $\mathbf{2 0 1 6}$ & $\mathbf{2 0 1 7}$ & $\mathbf{2 0 1 8}$ & $\mathbf{2 0 1 9}$ \\
\hline Low & $1.12 \%$ & $5.20 \%$ & $1.04 \%$ & $0.65 \%$ \\
Moderately low & $3.37 \%$ & $2.64 \%$ & $2.82 \%$ & $1.57 \%$ \\
Medium & $3.10 \%$ & $6.43 \%$ & $3.21 \%$ & $2.84 \%$ \\
Moderately high & $20.90 \%$ & $10.36 \%$ & $24.32 \%$ & $16.30 \%$ \\
High & $71.51 \%$ & $75.37 \%$ & $68.61 \%$ & $78.64 \%$ \\
\hline
\end{tabular}

\section{Discussion}

\subsection{Spatiotemporal Analysis}

Our study found that the spatial distribution of active fire in the Arctic is not completely random, but follow a clustered spatial distribution, which is consistent with the clustered spatial distribution pattern of fire in other regions, such as the Western United States [75] and the Amazon [76]. The occurrence of active fires depends on a complex and interacting set of factors, such as vegetation types, topographic conditions, climatic conditions, and human activities [75]. These factors are also the basis of our wildfire risk assessment model. The Siberian region of Russia, the region with the most active fires in the Arctic, has more vegetation and a large amount of dry biomass, which is consistent with Ponomarev et al. [40].

Most active fires occur in the summer, when temperatures are limited in other seasons. However, there are some regions where fires are active mostly in the spring, such as southeastern Siberia [41], where summer rainfall suppresses them. Active fires in the Arctic may occur in seasons when there is no lightning and vegetation is not dry enough [41].

Various spatial factors create the conditions for the occurrence of active fires [75], and these factors may change with time, leading to the recent increase of active fires in the Arctic. Among natural factors, topographic conditions are difficult to change, but climate and vegetation conditions may change, with vegetation change also affected by climate change [75]. Climate change affects wildfires [77] and is increasing the number of wildfires in the Northern Hemisphere [78]. This is due to increases in atmospheric $\mathrm{CO}_{2}$ concentration and temperature. First, rising temperatures and carbon emissions lead to longer growing seasons, increasing the biomass of forests and grasslands and, thus, increasing surface fuel loads. Moreover, rising temperatures increase atmospheric evaporation, which exacerbates droughts and increases the risk of wildfires, especially in forested areas where combustible materials are abundant [79]. Moreover, carbon emissions from wildfires in the Arctic, where peatlands store a lot of carbon, are likely to exacerbate climate warming. Second, global warming increases the amount of lightning in the temperate atmosphere [80]. Stocks et al. [81] found that in Canada's boreal forests, a single fire caused by lightning is much larger than a man-made fire. Lightning can explain more than $55 \%$ of the interannual fluctuations in wildfires in Alaska and northern Canada in recent years [82]. The temperature in 2019 was the second-highest in the Arctic's history, and rising temperatures have led to drier temperatures and more lightning which, in turn, has started more wildfires. Since the end of the 20th century, the Arctic has been warming more than twice as fast as the global average, a phenomenon known as "Arctic amplification" [83], so Arctic wildfires will become more frequent.

Previous studies $[84,85]$ have shown that there is also a remote correlation between sea surface temperature (SST) and fires, among which ENSO (El Niño-Southern Oscillation) is the most important SST driver. It can be predicted that the redistribution of precipitation by ENSO had led to extreme drought in 1/3 of the burned area of the world [84]. ENSO's redistribution of precipitation causes extreme drought [86]. The magnitude and duration of ENSO's effect on wildfires depend on the influence on forest fire weather and combustible characteristics [85]. ENSO has different effects in different regions. It contributes to wildfire risk in temperate Asia, East Africa, and equatorial Asia. ENSO is negatively correlated with growing season precipitation and combustible materials in northwest Australia, India, and South America, which limits the spread of wildfires [84]. Our study shows that years with 
a higher frequency of fires across the Arctic do not correlate well with years of ENSO or La Niña events (refer to Supplementary Material Tables S5 and S6 for specific time), so it is not clear how ENSO relates to Arctic wildfires. Kim et al. [41] showed that in positive-phase years in Siberia, ENSO increases late winter temperatures in Siberia, leading to more forest fires in the spring. In conclusion, climate change has some influence on wildfires, and the complex internal mechanism is worthy of further study. In addition, recent study [74] has identified a new atmospheric circulation pattern around the North Pole, called the circum-Arctic wave, which could lead to larger wildfires around the poles, especially in Siberia and the North American subpolar regions.

Human activities have a significant impact on the occurrence of wildfires by influencing the state of surface vegetation and combustible materials, actively generating fire sources and extinguishing catastrophic fires. Human activities affect not only the spatial distribution of wildfires, but also the fire system and distribution. In our study, the distance from roads and settlements was used to reflect the influence of human activities, and the results showed that surface human activities had a certain promoting effect on the occurrence of active fires. Mollicone et al. [87] found that the fire density of forests affected by human activities was 6-7 times that of original forests, which also indicated that human activities played a dominant role in forest fires in Russia. In addition, the clearing of some farmland, pastures and plantations has led to deforestation and peatland degradation, and fire is often used as a means of clearing the surface vegetation [88]. However, some studies [89-91] have found that human activity inhibits fire in other regions. For example, Archibald et al. [90] found that the number of fires on the African continent first increased and then decreased with population density. The burned area initially remained the same as population density increased, and then decreased with population density increasing. Andela et al. [91] found that there was a positive correlation between livestock density and wildfire area in humid tropical regions, and a negative correlation in arid/semi-arid tropical regions and temperate northern hemisphere regions. Some studies [89-91] have suggested that human activity inhibits fire, which is attributed to many aspects, such as man-made fire fighting, intensive management, surface fragmentation, and reduced fuel connectivity caused by human activity. The current relationship between human activity and active fire in the Arctic is consistent with earlier periods of lack of management in other regions. We hope that more governments will pay attention to the arctic fires, increase capital input, and introduce management measures to curb the development of active fires.

\subsection{Fire Risk Assessment Model}

Logistic regression analysis has frequently been used both to predict and also to determine the causation of fires. The AUC of the sample data (0.85) and verification data (0.93) showed good predictive ability, which is acceptable and higher than the AUC values in other literatures [92]. For example, Vilar del Hoyo et al. [92] obtained an AUC value of 0.67 to 0.70 in establishing the risk assessment of human-induced forest fires in southern Europe. The regression analysis of natural fires also showed good predictive ability when evaluated using the validation dataset. If we take the medium-high risk and high-risk points as the predicted fire points, the accuracy is the lowest $85.73 \%$, which is higher than the accuracy of other Logistic regression analysis-based fire risk assessment studies $[48,49,93]$. Even when we only used high-risk areas as the prediction points, the average accuracy rate was $73.53 \%$, which is comparable to other studies $[48,49,93]$. For example, Lozano et al. [48] estimated the risk of fire in the Mediterranean with an accuracy of $65-70 \%$. The Arctic is less disturbed by human factors, so fire risk assessments are more accurate.

Fire modelling represents a complex challenge, and its spread is usually related to several factors. In the current literatures [48-50], fire risk model input variables mainly include climate, topography, vegetation, and human factors. Our model contains the above factors. We used temperature, precipitation, and wind speed as climatic factors. Our 
results show that these factors have some influence on active fire, which is consistent with other studies.

Topography plays an important role in controlling the distribution of vegetation and wind speed, as well as rainfall speed and soil moisture [48-50]. It is highly recommended to include topographic variables when simulating fire occurrence, as Preisler et al. [46] concluded. The topographic factors in our model are elevation and slope, which also are consistent with other studies [48-50].

The vegetation factor used in our model is vegetation type. There is a significant correlation between fire danger and vegetation water content. Live vegetation water content can be expressed in different terms: the Fuel Moisture Content, the Equivalent Water Thickness, or the Relative Water Content [94]. However, the above vegetation water index needs to be acquired by field sampling, and we cannot obtain the data in a large area. In current studies, vegetation index (such as NDVI, EVI), vegetation type and other remote sensing indicators are mainly used to reflect the vegetation water content [50]. Some commonly used vegetation indices, such as NDVI and EVI, do not use the water absorption band; however, they are very sensitive to changes in leaf area and chlorophyll content associated with the drying process [50]. For each vegetation type, the vegetation water content behaviour can be better represented by a vegetation index [50]. In addition, the flammability and connectivity of each vegetation type are different, and our study also shows that vegetation type has a certain effect on active fire. NDVI was moderately correlated with vegetation types. Therefore, our model uses vegetation type as the model input variable.

In the representation of the impact of human activities on wildfires, commonly used indicators include population density, farmland area, stocking density and per capita GROSS national product (GDP). The effects of human activities on fire are mainly included in the fire model by using the empirical relationship between observed fires and these indicators. The Arctic is sparsely populated and involves different countries and regions, so such data are not easy to collect. We use distances to settlements and roads to reflect human activity, factors that have been used in many studies [48-50].

We do not have classified data on lightning fires to determine which active fires are lightning fires in the Arctic, but lightning fires account for 33-63\% of all forest fires in the United States and Canada [14]. Our study shows that lightning strike/lightning frequency has a certain effect on the occurrence of active fire, which is consistent with previous studies $[93,95]$. However, due to the coarse spatial resolution $\left(2.5^{\circ}\right)$ of the lightning data [61], we did not consider this factor in the risk assessment. In addition, the lightning data are averaged over the period 1995-2010 and are used to illustrate the high summer lightning density. Although the spatial and temporal pattern of lightning density may have changed between 2001 and 2019, the phenomenon of high summer lightning density should not change over time.

\subsection{Limitations and Prospects}

Our study did not distinguish the intensity or size of active fires. Small fires may not be detected due to the limited spatial resolution of remote sensing. Therefore, it has become a trend to develop more accurate fire point and spread area data based on satellite remote sensing technology. For example, the European Space Agency has been developing wildfire products with a spatial resolution of $10-30 \mathrm{~m}$ based on Landsat and Sentinel-2 satellite images. On the other hand, with the rapid development of unmanned aerial vehicle (UAV) technology, early warning of fires and fire situation monitoring at regional-landscape scales will become mainstream in the future. In addition, thermal infrared signals may not be able to monitor some fires due to the influence of cloudy weather, and microwave remote sensing detection will play an important role in the future. It is predicted that with the further improvement of space observation technology (e.g., Hyperspectral sensor, Lidar) and computing capacity, wildfire detection, monitoring and risk assessment technology will enter an era of high resolution and big data. 
The fire signal used in our study is relatively simple, that is, only the ground thermal infrared radiation signal in the fire area. In recent years, more comprehensive wildfire data have been obtained by using satellite remote sensing technology, which promotes the detection of multiple wildfire indicators and the comprehensive evaluation of temporal and spatial patterns and ecological effects [96]. Archibald et al. [96] comprehensively quantified the wildfire regime based on five factors: fire size, frequency, intensity, season, and extent. Furthermore, we cannot detect fires in underground peat at present. Therefore, we suggest that more indicator systems should be included in the monitoring of active fires in the Arctic in the future.

Although the Logistic regression model is regarded as one of the most effective models in the study of fire, it is a simple generalised linear model in essence, and it cannot realise more in-depth information mining for various related factors of fire. Therefore, deep neural network and other models with stronger ability to extract information from multiple factors may be used in the study of wildfire risk in subsequent studies.

With the development and integration of fire risk prediction models based on satellite remote sensing technology, global atmospheric general flow model, and dynamic vegetation model, building more complex fire dynamic mechanism model and revealing coupling dynamics of fire and climate change at different scales will be the future research direction. In addition, the future use of high-resolution remote sensing data, the establishment of a variety of fuel models, and dynamic study of fire behaviour at landscape scale will significantly improve the prediction ability of models and the reliability of results.

Finally, our study lacks field validation and field observation data. Although field observation data can only be limited to local areas, we suggest that in future studies, observation sites should be established for areas with high wild risk, and remote sensing and field data should be combined to provide certain support for fire observation and risk assessment.

\section{Conclusions}

Based on FIRMS MODIS C6 data from 2000 to 2019 and VIIRS V1 data from 2012 to 2019, we analysed the characteristics of spatial-temporal variation in active fires in the Arctic. A total of nine fire risk factors were selected from vegetation, topographic, meteorological, and human activity factors to quantitatively analyse the relationship between active fire frequency and fire risk factors. The fire risk factors were preprocessed by multicollinearity testing, correlation analysis, and difference significance testing, and a fire risk assessment model was built based on logistic regression. The accuracy of the model was verified and the evaluation results were analysed. The main conclusions are as follows:

(1) Throughout the Arctic, the active fire appears to be fluctuating but increasing overall.

(2) There is obvious seasonality, being concentrated in summer (June to August) and highest in July.

(3) Most active fires occur in Russia, followed by the United States and Canada's Yukon and Northwest Territories. The regions with increasing numbers of fires are mainly in Russia.

(4) The frequency of active fires is related to factors such as vegetation type, NDVI, elevation, slope, air temperature, precipitation, wind speed, distance from a road, and distance from a settlement.

(5) The risk assessment model based on logistic regression demonstrated good performance, and the analysis of the risk assessment results further illustrate its effectiveness.

Supplementary Materials: The following are available online at https:/ / www.mdpi.com/article/10.3 390/fire4030057/s1, Figure S1: The relationship between NDVI and the number of active fires in the Arctic region, Figure S2: The relationship between elevation and the frequency of active fires in the Arctic region, Figure S3: The elevation map in the Arctic region, Figure S4: The relationship between slope and the number of active fires in the Arctic region, Figure S5: The slope map in the Arctic region, Figure S6: The relationship between 2-m temperature and the number of active fires in the Arctic, Figure S7: The relationship between precipitation and the number of active fires in the Arctic region, 
Figure S8: The relationship between 10-m windspeed and the number of active fires in the Arctic region, Figure S9: The relationship between the distance from roads and the number of active fires in the Arctic region, Figure S10: The relationship between the distance from residential settlements and the number of active fires in the Arctic region, Figure S11: ROC curve, Table S1: Multicollinearity test for factors, Table S2: Correlation coefficient of factors, Table S3: Significant difference value of each factor between fire point and non-fire point, Table S4: The significance of factors in the sample group, Table S5 The 1990-2019 ENSO event, Table S6 The 1990-2019 La Niña event.

Author Contributions: Conceptualisation, Z.Z. and Z.D.; methodology, N.X.; software, N.X. and L.W.; validation, L.W.; formal analysis, N.X., and Z.Z.; investigation, N.X.; resources, Z.Z.; data curation, Z.Z.; writing-original draft preparation, Z.Z.; writing-review and editing, Z.Z., L.W. and Z.D.; visualisation, N.X. and L.W.; supervision, Z.Z.; project administration, Z.Z.; funding acquisition, Z.Z. All authors have read and agreed to the published version of the manuscript.

Funding: This research was funded by the National Natural Science Foundation of China (Grant No. 42071085), Open Project of the State Key Laboratory of Cryospheric Science (Grant No. SKLCS202010), and the National Nature Science Foundation of China (Grant No. 41701087).

Institutional Review Board Statement: Not applicable.

Informed Consent Statement: Not applicable.

Data Availability Statement: Not applicable.

Acknowledgments: We thank the United Nations Food and Agriculture Organization for providing the FIRMS data, NASA for providing MODIS and LIS/OSD data, European Space Agency for providing ERA-5 data, and Natural Earth website for providing populated places and roads data.

Conflicts of Interest: The authors declare no conflict of interest.

\section{References}

1. Zhang, X.; Hecobian, A.; Zheng, M.; Frank, N.H.; Weber, R.J. Biomass burning impact on PM2.5 over the southeastern US during 2007: Integrating chemically speciated FRM filter measurements, MODIS fire counts and PMF analysis. Atmos. Chem. Phys. 2010, 10, 6839-6853. [CrossRef]

2. Schultz, M.G.; Heil, A.; Hoelzemann, J.J.; Spessa, A.; Thonicke, K.; Goldammer, J.G.; Held, A.C.; Pereira, J.M.C.; van het Bolscher, M. Global wildland fire emissions from 1960 to 2000. Glob. Biogeochem. Cycles 2008, 22, 1-17. [CrossRef]

3. Bowd, E.J.; Banks, S.C.; Strong, C.L.; Lindenmayer, D.B. Long-term impacts of wildfire and logging on forest soils. Nat. Geosci. 2019, 12, 113-118. [CrossRef]

4. Tang, D.; Fan, H.; Yang, K.; Zhang, Y. Mapping forest disturbance across the China-Laos border using annual Landsat time series. Int. J. Remote Sens. 2018, 40, 2895-2915. [CrossRef]

5. Wu, C.; Venevsky, S.; Sitch, S.; Mercado, L.M.; Huntingford, C.; Staver, A.C. Historical and future global burned area with changing climate and human demography. One Earth 2021, 4, 517-530. [CrossRef]

6. Reisen, F.; Meyer, C.P.; Keywood, M.D. Impact of biomass burning sources on seasonal aerosol air quality. Atmos. Environ. 2013, 67, 437-447. [CrossRef]

7. Sun, Q.; Miao, C.; Hanel, M.; Borthwick, A.G.L.; Duan, Q.; Ji, D.; Li, H. Global heat stress on health, wildfires, and agricultural crops under different levels of climate warming. Environ. Int. 2019, 128, 125-136. [CrossRef]

8. Mack, M.C.; Walker, X.J.; Johnstone, J.F.; Alexander, H.D.; Melvin, A.M.; Jean, M.; Miller, S.N. Carbon loss from boreal forest wildfires offset by increased dominance of deciduous trees. Science 2021, 372, 280. [CrossRef] [PubMed]

9. Neff, J.C.; Harden, J.W.; Gleixner, G. Fire effects on soil organic matter content, composition, and nutrients in boreal interior Alaska. Can. J. For. Res. 2005, 35, 2178-2187. [CrossRef]

10. Hugelius, G.; Loisel, J.; Chadburn, S.; Jackson, R.B.; Jones, M.; MacDonald, G.; Marushchak, M.; Olefeldt, D.; Packalen, M.; Siewert, M.B.; et al. Large stocks of peatland carbon and nitrogen are vulnerable to permafrost thaw. Proc. Natl. Acad. Sci. USA 2020, 117, 20438-20446. [CrossRef]

11. McCarty, J.L.; Aalto, J.; Paunu, V.-V.; Arnold, S.R.; Eckhardt, S.; Klimont, Z.; Fain, J.J.; Evangeliou, N.; Venäläinen, A.; Tchebakova, N.M.; et al. Reviews \& Syntheses: Arctic Fire Regimes and Emissions in the 21st Century. Biogeosciences 2021, 1-59. (in review). [CrossRef]

12. Hugelius, G.; Strauss, J.; Zubrzycki, S.; Harden, J.W.; Schuur, E.A.G.; Ping, C.L.; Schirrmeister, L.; Grosse, G.; Michaelson, G.J.; Koven, C.D.; et al. Estimated stocks of circumpolar permafrost carbon with quantified uncertainty ranges and identified data gaps. Biogeosciences 2014, 11, 6573-6593. [CrossRef]

13. Nitze, I.; Grosse, G.; Jones, B.M.; Romanovsky, V.E.; Boike, J. Remote sensing quantifies widespread abundance of permafrost region disturbances across the Arctic and Subarctic. Nat. Commun. 2018, 9, 1-11. [CrossRef] [PubMed] 
14. Kasischke, E.S.; Turetsky, M.R. Recent changes in the fire regime across the North American boreal region-Spatial and temporal patterns of burning across Canada and Alaska. Geophys. Res. Lett. 2006, 33. [CrossRef]

15. Dozier, J. A method for satellite identification of surface temperature fields of subpixel resolution. Remote Sens. Environ. 1981, 11, 221-229. [CrossRef]

16. Langaas, S. A parametrised bispectral model for savanna fire detection using AVHRR night images. Int. J. Remote Sens. 2007, 14, 2245-2262. [CrossRef]

17. Lee, T.F.; Tag, P.M. Improved Detection of Hotspots using the AVHRR 3.7-um Channel. Bull. Am. Meteorol. Soc. 1990, 71, 1722-1730. [CrossRef]

18. Flasse, S.P.; Ceccato, P. A contextual algorithm for AVHRR fire detection. Int. J. Remote Sens. 1996, 17, 419-424. [CrossRef]

19. Chuvieco, E.; Martin, M.P. A simple method for Are growth mapping using AVHRR channel 3 data. Int. J. Remote Sens. 1994, 15, 3141-3146. [CrossRef]

20. Ardakani, A.S.; Zoej, M.J.V.; Mohammadzadeh, A.; Mansourian, A. Spatial and Temporal Analysis of Fires Detected by MODIS Data in Northern Iran from 2001 to 2008. IEEE J. Sel. Top. Appl. Earth Obs. Remote Sens. 2011, 4, 216-225. [CrossRef]

21. Palumbo, I.; Grégoire, J.M.; Simonetti, D.; Punga, M. Spatio-temporal distribution of fire activity in protected areas of Sub-Saharan Africa derived from MODIS data. Procedia Environ. Sci. 2011, 7, 26-31. [CrossRef]

22. Wei, X.; Wang, G.; Chen, T.; Hagan, D.F.T.; Ullah, W. A Spatio-Temporal Analysis of Active Fires over China during $2003-2016$. Remote Sens. 2020, 12, 1787. [CrossRef]

23. Molinario, G.; Davies, D.K.; Schroeder, W.; Justice, C.O. Characterizing the spatio-temporal fire regime in Ethiopia using the MODIS-active fire product: A replicable methodology for country-level fire reporting. Afr. Geogr. Rev. 2013, 33, 99-123. [CrossRef]

24. Giglio, L.; Csiszar, I.; Restás, Á.; Morisette, J.T.; Schroeder, W.; Morton, D.; Justice, C.O. Active fire detection and characterization with the advanced spaceborne thermal emission and reflection radiometer (ASTER). Remote Sens. Environ. 2008, 112, 3055-3063. [CrossRef]

25. Schroeder, W.; Oliva, P.; Giglio, L.; Quayle, B.; Lorenz, E.; Morelli, F. Active fire detection using Landsat-8/OLI data. Remote Sens. Environ. 2016, 185, 210-220. [CrossRef]

26. Hu, X.; Ban, Y.; Nascetti, A. Sentinel-2 MSI data for active fire detection in major fire-prone biomes: A multi-criteria approach. Int. J. Appl. Earth Obs. 2021, 101, 102347. [CrossRef]

27. Csiszar, I.; Denis, L.; Giglio, L.; Justice, C.O.; Hewson, J. Global fire activity from two years of MODIS data. Int. J. Wildland Fire 2005, 14, 117-130. [CrossRef]

28. Hantson, S.; Padilla, M.; Corti, D.; Chuvieco, E. Strengths and weaknesses of MODIS hotspots to characterize global fire occurrence. Remote Sens. Environ. 2013, 131, 152-159. [CrossRef]

29. Smith, R.; Adams, M.; Maier, S.; Craig, R.; Kristina, A.; Maling, I. Estimating the area of stubble burning from the number of active fires detected by satellite. Remote Sens. Environ. 2007, 109, 95-106. [CrossRef]

30. Li, P.; Xiao, C.; Feng, Z.; Li, W.; Zhang, X. Occurrence frequencies and regional variations in Visible Infrared Imaging Radiometer Suite (VIIRS) global active fires. Glob. Chang. Biol. 2020, 26, 2970-2987. [CrossRef]

31. Waigl, C.F.; Stuefer, M.; Prakash, A.; Ichoku, C. Detecting high and low-intensity fires in Alaska using VIIRS I-band data: An improved operational approach for high latitudes. Remote Sens. Environ. 2017, 199, 389-400. [CrossRef]

32. Yaduvanshi, A.; Srivastava, P.K.; Pandey, A.C. Integrating TRMM and MODIS satellite with socio-economic vulnerability for monitoring drought risk over a tropical region of India. Phys. Chem. Earth Parts A/B/C 2015, 83-84, 14-27. [CrossRef]

33. Vadrevu, K.; Lasko, K. Intercomparison of MODIS AQUA and VIIRS I-Band Fires and Emissions in an Agricultural Landscape-Implications for Air Pollution Research. Remote Sens. 2018, 10, 978. [CrossRef]

34. Voulgarakis, A.; Field, R.D. Fire Influences on Atmospheric Composition, Air Quality and Climate. Curr. Pollut. Rep. 2015, 1, 70-81. [CrossRef]

35. Csiszar, I.A.; Schroeder, W. Short-Term Observations of the Temporal Development of Active Fires from Consecutive Same-Day ETM+ and ASTER Imagery in the Amazon: Implications for Active Fire Product Validation. IEEE J. Sel. Top. Appl. Earth Obs. Remote Sens. 2008, 1, 248-253. [CrossRef]

36. Xu, W.; Wooster, M.J.; Roberts, G.; Freeborn, P. New GOES imager algorithms for cloud and active fire detection and fire radiative power assessment across North, South and Central America. Remote Sens. Environ. 2010, 114, 1876-1895. [CrossRef]

37. Freeborn, P.; Wooster, M.; Roberts, G.; Xu, W. Evaluating the SEVIRI Fire Thermal Anomaly Detection Algorithm across the Central African Republic Using the MODIS Active Fire Product. Remote Sens. 2014, 6, 1890-1917. [CrossRef]

38. Vivchar, A. Wildfires in Russia in 2000-2008: Estimates of burnt areas using the satellite MODIS MCD45 data. Remote Sens. Lett. 2011, 2, 81-90. [CrossRef]

39. Yen, M.-C.; Peng, C.-M.; Chen, T.-C.; Chen, C.-S.; Lin, N.-H.; Tzeng, R.-Y.; Lee, Y.-A.; Lin, C.-C. Climate and weather characteristics in association with the active fires in northern Southeast Asia and spring air pollution in Taiwan during 2010 7-SEAS/Dongsha Experiment. Atmos. Environ. 2013, 78, 35-50. [CrossRef]

40. Ponomarev, E.; Yakimov, N.; Ponomareva, T.; Yakubailik, O.; Conard, S.G. Current Trend of Carbon Emissions from Wildfires in Siberia. Atmosphere 2021, 12, 559. [CrossRef]

41. Kim, J.-S.; Kug, J.-S.; Jeong, S.-J.; Park, H.; Schaepman-Strub, G. Extensive fires in southeastern Siberian permafrost linked to preceding Arctic Oscillation. Sci. Adv. 2020, 6, 1-8. [CrossRef] 
42. Ziel, R.H.; Bieniek, P.A.; Bhatt, U.S.; Strader, H.; Rupp, T.S.; York, A. A Comparison of Fire Weather Indices with MODIS Fire Days for the Natural Regions of Alaska. Forests 2020, 11, 516. [CrossRef]

43. Novo, A.; Fariñas-Álvarez, N.; Martínez-Sánchez, J.; González-Jorge, H.; Fernández-Alonso, J.M.; Lorenzo, H. Mapping Forest Fire Risk-A Case Study in Galicia (Spain). Remote Sens. 2020, 12, 3705. [CrossRef]

44. Garcia, C.V.; Woodard, P.M.; Titus, S.J.; Adamowicz, W.L.; Lee, B.S. A Logit Model for Predicting the Daily Occurrence of Human Caused Forest-Fires. Int. J. Wildland Fire 1995, 5, 101. [CrossRef]

45. Cardille, J.A.; Ventura, S.J.; Monica, A.; Turner, G. Environmental and social factors influencing wildfires in the Upper Midwest, United States. Ecol. Appl. 2001, 11, 111-127. [CrossRef]

46. Preisler, H.K.; Brillinger, D.R.; Burgan, R.E.; Benoit, J.W. Probability based models for estimation of wildfire risk. Int. J. Wildland Fire 2004, 13, 133. [CrossRef]

47. Rollins, M.G.; Keane, R.E.; Parsons, R.A. Mapping Fuels and Fire Regimes Using Remote Sensing, Ecosystem Simulation, and Gradient Modeling. Ecol. Appl. 2004, 14, 75-95. [CrossRef]

48. Lozano, F.J.; Suárez-Seoane, S.; de Luis, E. Assessment of several spectral indices derived from multi-temporal Landsat data for fire occurrence probability modelling. Remote Sens. Environ. 2007, 107, 533-544. [CrossRef]

49. Chang, Y.; Zhu, Z.; Bu, R.; Chen, H.; Feng, Y.; Li, Y.; Hu, Y.; Wang, Z. Predicting fire occurrence patterns with logistic regression in Heilongjiang Province, China. Landsc. Ecol. 2013, 28, 1989-2004. [CrossRef]

50. Bisquert, M.M.; Sa'nchez, J.M.; Caselles, V. Fire danger estimation from MODIS Enhanced Vegetation Index data_application to Galicia region (north-west Spain). Int. J. Wildland Fire 2011, 20, 465-473. [CrossRef]

51. Bisquert, M.; Caselles, E.; Sánchez, J.M.; Caselles, V. Application of artificial neural networks and logistic regression to the prediction of forest fire danger in Galicia using MODIS data. Int. J. Wildland Fire 2012, 21, 1025. [CrossRef]

52. Parisien, M.-A.; Snetsinger, S.; Greenberg, J.A.; Nelson, C.R.; Schoennagel, T.; Dobrowski, S.Z.; Moritz, M.A. Spatial variability in wildfire probability across the western United States. Int. J. Wildland Fire 2012, 21, 313. [CrossRef]

53. Lozano, F.J.; Suárez-Seoane, S.; Kelly, M.; Luis, E. A multi-scale approach for modeling fire occurrence probability using satellite data and classification trees: A case study in a mountainous Mediterranean region. Remote Sens. Environ. 2008, 112, 708-719. [CrossRef]

54. Mohajane, M.; Costache, R.; Karimi, F.; Bao Pham, Q.; Essahlaoui, A.; Nguyen, H.; Laneve, G.; Oudija, F. Application of remote sensing and machine learning algorithms for forest fire mapping in a Mediterranean area. Ecol. Indic. 2021, 129, 107869. [CrossRef]

55. Wang, J.; Zhao, Y.; Li, C.; Yu, L.; Liu, D.; Gong, P. Mapping global land cover in 2001 and 2010 with spatial-temporal consistency at $250 \mathrm{~m}$ resolution. ISPRS J. Photogramm. Remote Sens. 2015, 103, 38-47. [CrossRef]

56. Bintanja, R. The impact of Arctic warming on increased rainfall. Sci. Rep. 2018, 8, 16001. [CrossRef] [PubMed]

57. van der Werf, G.R.; Randerson, J.T.; Giglio, L.; van Leeuwen, T.T.; Chen, Y.; Rogers, B.M.; Mu, M.; van Marle, M.J.E.; Morton, D.C.; Collatz, G.J.; et al. Global fire emissions estimates during 1997-2016. Earth Syst. Sci. Data 2017, 9, 697-720. [CrossRef]

58. Li, F.; Zhang, X.; Kondragunta, S.; Csiszar, I. Comparison of Fire Radiative Power Estimates from VIIRS and MODIS Observations. J. Geophys. Res. Atmos. 2018, 123, 4545-4563. [CrossRef]

59. Sharma, A.; Wang, J.; Lennartson, E. Intercomparison of MODIS and VIIRS Fire Products in Khanty-Mansiysk Russia: Implications for Characterizing Gas Flaring from Space. Atmosphere 2017, 8, 95. [CrossRef]

60. Sulla-Menashe, D.; Gray, J.M.; Abercrombie, S.P.; Friedl, M.A. Hierarchical mapping of annual global land cover 2001 to present: The MODIS Collection 6 Land Cover product. Remote Sens. Environ. 2019, 222, 183-194. [CrossRef]

61. Cecil, D.J.; Buechler, D.E.; Blakeslee, R.J. Gridded lightning climatology from TRMM-LIS and OTD: Dataset description. Atmos. Res. 2014, 135, 404-414. [CrossRef]

62. Theil, H. A rank-invariant method of linear and polynomial regression analysis. Indag. Math. 1950, 12, 386-392.

63. Sen, P.K. Estimates of the Regression Coefficient Based on Kendall's Tau. J. Am. Stat. Assoc. 1968, 63, 1379-1389. [CrossRef]

64. Mann, H.B. Nonparametric tests against trend. Econom. J. Econom. Soc. 1945, 13, 245-259. [CrossRef]

65. Hamed, K.H.; Ramachandra Rao, A. A modified Mann-Kendall trend test for autocorrelated data. J. Hydrol. 1998, 204, 182-196. [CrossRef]

66. Mitchell, A. The ESRI Guide to GIS Analysis, Volume 2; ESRI Press: New York, NY, USA, 2005.

67. Haitovsky, Y. Multicollinearity in Regression Analysis: Comment. Rev. Econ. Stat. 1969, 51, 486. [CrossRef]

68. Norušis, M.J. SPSS Introductory Guide: Basic Statistics and Operations; SPSS: Chicago, IL, USA, 1982.

69. Marquaridt, D.W. Generalized Inverses, Ridge Regression, Biased Linear Estimation, and Nonlinear Estimation. Technometrics 1970, 12, 591-612. [CrossRef]

70. Wang, Q.; Koval, J.J.; Mills, C.A.; Lee, K.-I.D. Determination of the Selection Statistics and Best Significance Level in Backward Stepwise Logistic Regression. Commun. Stat. Simul. Comput. 2007, 37, 62-72. [CrossRef]

71. Swets, J.A. Signal Detection Theory and ROC Analysis in Psychology and Diagnostics: Collected Papers; Psychology Press: Mahwah, NJ, USA, 1996.

72. Lindsey, R. Arctic Report Card: Visual Highlights. 2019. Available online: https://www.climate.gov/news-features/ understanding-climate/2019-arctic-report-card-visual-highlights (accessed on 1 July 2021).

73. Holden, Z.A.; Jolly, W.M. Modeling topographic influences on fuel moisture and fire danger in complex terrain to improve wildland fire management decision support. For. Ecol. Manag. 2011, 262, 2133-2141. [CrossRef] 
74. Yasunari, T.J.; Nakamura, H.; Kim, K.-M.; Choi, N.; Lee, M.-I.; Tachibana, Y.; da Silva, A.M. Relationship between circum-Arctic atmospheric wave patterns and large-scale wildfires in boreal summer. Environ. Res. Lett. 2021, 16, 064009. [CrossRef]

75. Weber, K.T.; Yadav, R. Spatiotemporal Trends in Wildfires across the Western United States (1950-2019). Remote Sens. 2020, 12, 2959. [CrossRef]

76. Alencar, A.A.; Brando, P.M.; Asner, G.P.; Putz, F.E. Landscape fragmentation, severe drought, and the new Amazon forest fire regime. Ecol. Appl. 2015, 25, 1493-1505. [CrossRef]

77. Duane, A.; Brotons, L. Synoptic weather conditions and changing fire regimes in a Mediterranean environment. Agric. For. Meteorol. 2018, 253-254, 190-202. [CrossRef]

78. Di Virgilio, G.; Evans, J.P.; Blake, S.A.P.; Armstrong, M.; Dowdy, A.J.; Sharples, J.; McRae, R. Climate Change Increases the Potential for Extreme Wildfires. Geophys. Res. Lett. 2019, 46, 8517-8526. [CrossRef]

79. Kasischke, E.S.; Verbyla, D.L.; Rupp, T.S.; McGuire, A.D.; Murphy, K.A.; Jandt, R.; Barnes, J.L.; Hoy, E.E.; Duffy, P.A.; Calef, M.; et al. Alaska's changing fire regime-Implications for the vulnerability of its boreal. Can. J. For. Res. 2010, 40, 1313-1324. [CrossRef]

80. Sedano, F.; Randerson, J.T. Multi-scale influence of vapor pressure deficit on fire ignition and spread in boreal forest ecosystems. Biogeosciences 2014, 11, 3739-3755. [CrossRef]

81. Stocks, B.J.; Mason, J.A.; Todd, J.B.; Bosch, E.M.; Wotton, B.M.; Amiro, B.D.; Flannigan, M.D.; Hirsch, K.G.; Logan, K.A.; Martell, D.L.; et al. Large forest fires in Canada, 1959-1997. J. Geophys. Res. 2002, 108, FFR 5-1-FFR 5-12. [CrossRef]

82. Veraverbeke, S.; Rogers, B.M.; Goulden, M.L.; Jandt, R.R.; Miller, C.E.; Wiggins, E.B.; Randerson, J.T. Lightning as a major driver of recent large fire years in North American boreal forests. Nat. Clim. Chang. 2017, 7, 529-534. [CrossRef]

83. Serreze, M.C.; Barry, R.G. Processes and impacts of Arctic amplification: A research synthesis. Glob. Planet. Chang. 2011, 77, 85-96. [CrossRef]

84. Chen, Y.; Morton, D.C.; Andela, N.; Giglio, L.; Randerson, J.T. How much global burned area can be forecast on seasonal time scales using sea surface temperatures? Environ. Res. Lett. 2016, 11, 045001. [CrossRef]

85. Chen, Y.; Morton, D.C.; Andela, N.; van der Werf, G.R.; Giglio, L.; Randerson, J.T. A pan-tropical cascade of fire driven by El Niño/Southern Oscillation. Nat. Clim. Chang. 2017, 7, 906-911. [CrossRef]

86. Siegert, F.; Ruecker, G.; Hinrichs, A.; Hoffmann, A.A. Increased damage from fires in logged forests during droughts caused by El Niño. Nature 2001, 414, 437-440. [CrossRef]

87. Mollicone, D.; Eva, H.D.; Achard, F. Human role in Russian wild fires. Nature 2006, 440, 435-436. [CrossRef]

88. Morton, D.C. Changes in Amazon Forest Structure from Land-Use Fires: Integrating Satellite Remote Sensing and Ecosystem Modeling; University of Maryland: College Park, MD, USA, 2008.

89. Bistinas, I.; Harrison, S.P.; Prentice, I.C.; Pereira, J.M.C. Causal relationships versus emergent patterns in the global controls of fire frequency. Biogeosciences 2014, 11, 5087-5101. [CrossRef]

90. Archibald, S.; Roy, D.P. Identifying individual fires from satellite-derived burned area data. In Proceedings of the 2009 IEEE International Geoscience and Remote Sensing Symposium, Cape Town, South Africa, 12-17 July 2009; pp. III-160-III-163. [CrossRef]

91. Andela, N.; Morton, D.C.; Giglio, L.; Chen, Y.; van der Werf, G.R.; Kasibhatla, P.S.; DeFries, R.S.; Collatz, G.J.; Hantson, S.; Kloster, S.; et al. A human-driven decline in global burned area. Science 2017, 356, 1356-1361. [CrossRef]

92. Vilar del Hoyo, L.; Martín Isabel, M.P.; Martínez Vega, F.J. Logistic regression models for human-caused wildfire risk estimation: Analysing the effect of the spatial accuracy in fire occurrence data. Eur. J. For. Res. 2011, 130, 983-996. [CrossRef]

93. Castedo Dorado, F.; León, U.D.Y.E.S.; Agraria, T.D.I.; Rodríguez Pérez, J.R.; León, U.D.; Superiory, E.; Minas, T.D.I.D.; Marcos Menéndez, J.L. Modelling the probability of lightning-induced forest fire occurrence in the province of León (NW Spain). For. Syst. 2011, 20, 95-107. [CrossRef]

94. Maki, M.; Ishiahra, M.; Tamura, M. Estimation of leaf water status to monitor the risk of forest fires by using remotely sensed data. Remote Sens. Environ. 2004, 90, 441-450. [CrossRef]

95. Krawchuk, M.A.; Cumming, S.G.; Flannigan, M.D. Predicted changes in fire weather suggest increases in lightning fire initiation and future area burned in the mixedwood boreal forest. Clim. Chang. 2008, 92, 83-97. [CrossRef]

96. Archibald, S.; Lehmann, C.E.R.; Gomez-Dans, J.L.; Bradstock, R.A. Defining pyromes and global syndromes of fire regimes. Proc. Natl. Acad. Sci. USA 2013, 110, 6442-6447. [CrossRef] 